\title{
POLÍTICAS E PRÁTICAS PEDAGÓGICAS ENVOLVIDAS NA PROMOÇÃO DE POTENCIALIDADES DA ESCOLA PARA O IMPULSIONAMENTO DO PROTAGONISMO INFANTO - JUVENIL: UMA REVISÃO
}

\begin{abstract}
Amilka Karla Ferraz de Melo ${ }^{1}$
RESUMO: Introdução: Precisa-se de políticas pedagógicas que contribuam para a disseminação do conhecimento e poder a população infanto-juvenil. Objetivo: o objetivo deste estudo foi compreender como as políticas e práticas pedagógicas envolvidas na promoção de potencialidades da escola para o impulsionamento do protagonismo infanto - juvenil. Materiais e Métodos: Foi realizada uma pesquisa bibliográfica nas bases de dados do Google Scholar e Scielo em maio de 2021. A busca permitiu a identificação de seis artigos que se enquadraram nos critérios estabelecidos. Resultados: Os artigos realizam reflexões sobre questões de cunho social envolvendo a educação infanto-juvenil, abordando o conceito de protagonismo $\mathrm{e}$ as diretrizes legais dos documentos pedagógicos, onde se mostra como um dos mecanismos de fortalecimento da educação para a cidadania ética. Conclusão: Assim podemos concluir que o papel apesar das práticas e políticas pedagógicas é promover a cidadania e a participação efetiva de alunos, gestores e educadores no desenvolvimento da sociedade.
\end{abstract}

Palavras chave: Protagonismo Infanto-juvenil. Práticas Pedagógicas. Escola.

ABSTRACT: Introduction: Today's society requires attitudes that add critical values through the application of pedagogical practices and policies that contribute to the dissemination of knowledge and power to children and adolescents. Objective: the objective of this study was to understand how the pedagogical policies and practices involved in promoting the potential of the school to boost the role of children and youth. Materials and Methods: A literature search was carried out in Google Scholar and Scielo databases in May 2021. The search allowed the identification of six articles that met the established criteria. Results: : The articles reflect on social issues involving education in children and adolescents, addressing the concept of protagonism and the legal guidelines of pedagogical documents, where it is shown as one of the mechanisms for strengthening education for ethical citizenship. Conclusion: Thus we can conclude that the role despite pedagogical practices and policies is to promote citizenship and the effective participation of students, managers and educators in the development of society.

Keywords: Child and Youth Protagonism. Pedagogical practices. School.

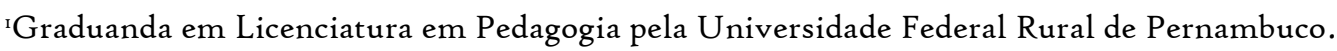




\section{INTRODUÇÃO}

O protagonismo juvenil é responsável por calorosas discussões na atualidade. Este se tornou ainda mais enfático na área educacional partir da reforma curricular do ensino médio que adotara o conceito como um dos pilares de inovação (JESUS, 2020).

Neste sentido, a escola é entendida como local onde o indivíduo recebe ideias que irão permear as suas decisões na sociedade, formando jovens autônomos, solidários e competente, responsáveis por transformações sociais (SOUZA; SOUZA, 2019).

No entanto, tal assunto ainda não conta com uma definição singular, pois se permeia de inúmeros conceitos que ainda não contém conceituações, porém são paradoxos para uma emancipação dos jovens (SILVA et al, 2018).

Desse modo, os conceitos relacionados ao protagonismo juvenil são vistos como uma proposta emancipatória, onde são utilizados não somente para a resolução de urgências sociais, mas também para angústias pessoais na vida dos jovens (PEREIRA, 2020).

Neste sentido, é uma necessidade da atualidade se aprofundar e contextualizar as reflexões sobre o protagonismo juvenil, abordando os conceitos teóricos e os objetivos das práticas e políticas pedagógicas que podem ser aplicadas.

Bem como, sem menção a eventos externos, caracterizar a participação ou referência a ações e experiências de protagonismo fora do ambiente escolar, sendo o tema principal dessas iniciativas os jovens cada vez mais ativos em questões sociais e políticas na sociedade (SOUZA; SOUZA, 2019).

Portanto, a falta de elementos característicos do conceito de protagonismo

juvenil, que surgiu no contexto da luta de classes fora responsável por muitas transformações sociais, todavia os saberes socializados denotam uma concepção de protagonismo alheia à participação social (SILVA, 2019).

As práticas e políticas aplicadas que regem a educação no Brasil estabelecem diretrizes e bases da educação nacional que especificam que o aluno deve ser preparado para o trabalho e para o exercício da cidadania (TOGETTA E DAUD, 2020). 
Dito isso, segundo Bueno (2000) as mudanças que a reforma propicia ao ensino, configuram-se de estratégias para preparação do jovem ao mercado de trabalho, não somente como apelo ao individualismo, mas também na configuração de visões produtivistas.

Isso se deve ao fato de que construindo uma educação pautada em interesses da sociedade civil e ao mesmo tempo permitindo que ocorram debates de cunho pedagógicos nas escolas, a fim de compreender os fenômenos sociológicos que mobilizam a população infanto-juvenil (SOUZA; SOUZA, 2019).

Isto é, perante tal paradigma o protagonismo infanto-juvenil é considerado uma forma de reduzir as dificuldades que estes encontram no mundo, ou seja, desemprego, desigualdades sociais e econômicas, entre outras (SILVA et al, 2018).

Desta forma, esta pesquisa se faz importante na sociedade atual devido o avanço tecnológico e científico, marcado de várias consequências sociais que exige uma sociedade posturas cada vez mais desafiadoras no que tange trabalho, educação, sociedade e valores. Acrescentando valores críticos através da apresentação e práticas e políticas pedagógicas que contribuam para a disseminação do conhecimento e poder que a população infanto-juvenil pode alcançar através de uma formação crítica de fenômenos sociológicos.

Por isso, o objetivo do presente estudo foi realizar uma revisão integrativa da literatura a fim de compreender as políticas e práticas pedagógicas envolvidas na promoção de potencialidades da escola para o impulsionamento do protagonismo infanto - juvenil.

\section{MATERIAIS E MÉTODOS}

Este estudo trata-se de uma revisão literária sendo a coleta dos dados realizada nas bases de dados: Google Acadêmico e periódicos Capes, onde foram selecionados artigos científicos indexados e publicado nos últimos 5 anos.

Para a realização deste trabalho foram selecionados artigos na língua inglesa e portuguesa a partir das seguintes palavras chaves: infanto-juvenil, práticas educacionais, políticas educacionais, educação, práticas pedagógicas, protagonismo juvenil. 
Foram utilizados como critérios de inclusão artigos que abordavam as práticas e políticas pedagógicas aplicadas no ensino infanto- juvenil, e também estudos que caracterizam a formação e conceito do protagonismo em jovens.

Foram utilizados como critérios de exclusão os artigos que tenham caracterizações diferentes deste estudo e faixa etária escolar diferente do grupo estudado.

A pesquisa foi realizada no mês de maio de 2021, terminando dentro do mesmo mês, utilizando os descritores: infanto-juvenil and práticas pedagógicas and protagonismo juvenil and políticas educacionais em português, e para pesquisas em inglês foram utilizados os termos: children and youth and pedagogical practices and youth protagonism and educational policies. Em ambas as bases de dados, sendo encontrados I040 estudos e selecionados seis artigos conforme figura I.

FIGURA I. FLUXOGRAMA E CRITÉRIOS DE SELEÇÃO E INCLUSÃO DOS ARTIGOS

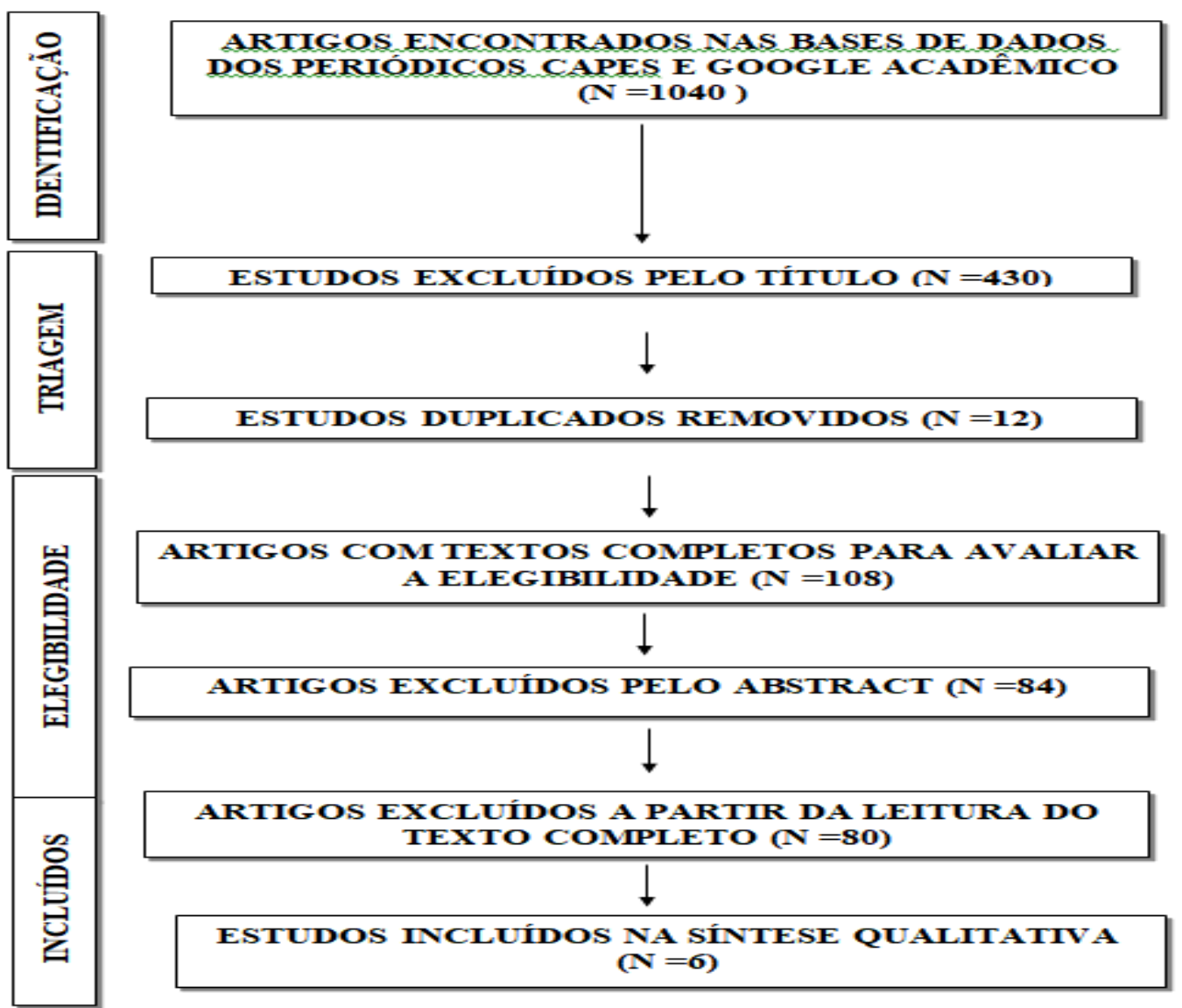




\section{RESULTADOS}

Quando nos referimos ao protagonismo juvenil, neste estudo, estamos nos referindo a adolescentes como personagem principal de uma ação voltada para a solução de problemas reais, ou seja, a participação ativa e construtiva do estudante na sua escola, na sua comunidade ou na sociedade em geral.

Assim, esta participação propositiva, proativa, só se desenvolve em ambientes democráticos onde o objetivo é a formação de cidadãos autônomos, solidários e compromissados.

A participação autêntica se traduz para o jovem num ganho de autonomia, autoconfiança e autodeterminação numa fase da vida em que ele se procura se conhecer e ter experiências que contribuam na construção da sua identidade pessoal e social. 
Tabela I - Demonstrativo dos artigos

\begin{tabular}{|c|c|c|c|c|c|c|}
\hline$\# \mathbf{N}$ & Data & Título & Autores & Periódico & Objetivos & Resultados \\
\hline or & 2020 & $\begin{array}{l}\text { Protagonismo juvenil } \\
\text { na Escola Cidadã } \\
\text { Integral: da concepção } \\
\text { às vivências }\end{array}$ & $\begin{array}{l}\text { PEREIRA, } \\
\text { Rosymere }\end{array}$ & UFCG & $\begin{array}{l}\text { O objetivo desta pesquisa foi } \\
\text { compreender a concep̧ão de } \\
\text { Protagonismo Juvenil para os/as } \\
\text { jovens de uma Escola Cidadã } \\
\text { Integral e Técnica - ECITE, } \\
\text { assim como, analisar a } \\
\text { abordagem dessa categoria pelo } \\
\text { referido modelo de escola. }\end{array}$ & $\begin{array}{l}\text { Nesse sentido de que } \\
\text { existem possibilidades e } \\
\text { construções históricas nos } \\
\text { espaços de contradição, } \\
\text { principalmente em tempos } \\
\text { tão desafiantes como o que } \\
\text { vivemos, reafirmamos que } \\
\text { esperançar é mais do que } \\
\text { preciso, é uma tarefa urgente } \\
\text { principalmente para a classe } \\
\text { trabalhadora e os/as } \\
\text { descendentes desta, pois são } \\
\text { estes sujeitos que fazem as } \\
\text { rodas da história girar. }\end{array}$ \\
\hline 02 & 2020 & $\begin{array}{l}\text { Escola do Campo: } \\
\text { quais as possibilidades } \\
\text { de inovação nas } \\
\text { práticas pedagógicas }\end{array}$ & $\begin{array}{l}\text { SILVA, Suse } \\
\text { Gomes da Costa }\end{array}$ & $\begin{array}{l}\text { Revistas eletronigas } \\
\text { Puc RS }\end{array}$ & $\begin{array}{l}\text { Compreende-se que são } \\
\text { necessários novos olhares para a } \\
\text { inovação no ensino superior, } \\
\text { visando a importância de práticas } \\
\text { diferenciadas e de ações que } \\
\text { potencializle@̣ßg o engajamento } \\
\text { acadêmico }\end{array}$ & $\begin{array}{l}\text { Refletir sobre a inovação no } \\
\text { ensino superior, sobre as } \\
\text { possibilidades de realização } \\
\text { de práticas pedagógicas } \\
\text { inovadoras, e sobre quais } \\
\text { delas favorecem o } \\
\text { engajamento acadêmico. A } \\
\text { inovação no ensino superior } \\
\text { depende de diversos fatores, } \\
\text { desde o apoio institucional } \\
\text { até o conhecimento docente }\end{array}$ \\
\hline
\end{tabular}


sobre o entendimento de práticas inovadoras. Nas instituições de ensino, é preciso promover capacitações para o aperfeiçoamento pedagógico e para estimular os docentes a propor inovações pedagógicas na sala de aula. As analisar as produções científicas sobre o tema da inovação, identificou-se que elas apresentam estratégias pedagógicas que possibilitam a integração de metodologias de ensino e de tecnologias no ensino superior, com o objetivo de contribuir para inovação dos processos de ensino 


\section{O protagonismo \\ infanto-juvenil e suas}

BATISTA, Marisa

competências

empreendedoras como

iniciativas educativas $e$

profissionais numa

organização social e

ética

Protagonismo juvenil JESUS, Leandra no diálogo sobre água: Fernandes Alves de

um relato

experiência sobre a

conferência de meio

ambiente na escola
Revista Brasileira do Ensino Médio-

RBRAEM

Revista Atena

sta Brasileira do
AEM Médio-

Os objetivos do trabalho é Ficou concluído que o elencar os aspectos positivos e envolvimento dos estudantes negativos de organizar e possibilita desenvolver uma conferência na desenvolvimento

escola, além de demonstrar a pensamento importância envolver estudantes em debates. 040

Identificar em uma escola na periferia de São Paulo no Brasil

se são sujeitos de direitos e militam em prol do
desenvolvimento sustentável do planeta.

autonomia nas fala

desinibição em discursos, tornando-os protagonistas 
$\begin{array}{lll}\text { A mediação escolar SOUZA, Edsonia } \\ \text { como } & \text { método Jadma Marcelino; }\end{array}$

adequado de solução SOUZA Alexander

de

fortalecimento e Pelissari

protagonismo juvenil
Revista temas e $O$ presente trabalho tem como $O$ uso do instituto da matizes

perspectiva refletir as

transformaçoes na sociedade mediação como método adequado

de solução dos conflitos comunidade escolar.

tem a capacidade de romper com o sentimento conflitante, estabelecendo entre aspartes a capacidade de dialogar.
Revista eletrônica d psicologia epistemologia genéticas de O objetivo do trabalho fora

abordar a natureza da educação e as questões éticas envolvidas, compreendendo o papel do protagonismo infanto-juvenil na escola.
Paulino; DAUD Rafael Petta.
Conclui-se que os alunos podem desenvolver papel de protagonismo e ser atuantes na formação da escola. Revela ainda que a escola precisa de um olhar mais atento a questões de cunho social, cuidando para que professores e alunos convivam de forma pacifica. 


\section{DISCUSSÃO}

O objetivo do presente estudo foi realizar uma revisão integrativa da literatura a fim de compreender as políticas e práticas pedagógicas envolvidas na promoção de potencialidades da escola para o impulsionamento do protagonismo infanto-juvenil.

Para o artigo realizado foram encontradas dificuldades quanto à pesquisa bibliográfica, uma vez que, as delimitações definidas de idiomas em português e inglês fizeram com que diversos artigos fossem excluídos na etapa de seleção. Além disso, percebeu-se um grande número de pesquisas duplicadas nas bases de dados e escassez de estudos recentes sobre o assunto.

Compreender o cotidiano de jovens e adolescentes é fundamental para o desenvolvimento de propostas e mecanismos educacionais eficazes e que respondam aos anseios e necessidades dessa população e da sociedade em geral (SOUZA; SOUZA, 2019).

Assim, a prática pedagógica pode ser entendida como a expressão de uma determinada relação social, sendo estes conteúdos mutáveis que variam de acordo com a história da atualidade, baseada em questões de cunhos sociais e econômicos (LIBÂNEO apud SILVA, 2019).

Desta forma, entender o protagonismo infanto-juvenil se faz fundamental para o presente estudo. De acordo com Togetta e Daud (2020), a juventude deve ser entendida como uma sociedade de valores, morais e crenças, que representam ideologias ainda não vividas.

Sob essa perspectiva, entende-se que o jovem é educado para ser peça fundamental, ou seja, o protagonista, no seu processo educacional, contribuindo na formação de valores criticamente, a fim de exercer plena cidadania e ser capaz de participar de decisões ao bem comum (PEREIRA, 2020).

Neste sentido, Batista (2020) corrobora esta ideia afirmando que o protagonismo infanto-juvenil pode ser entendido como a voz de indivíduos que realizam ações para o bem próprio e da sociedade. 
Então, o protagonismo infanto-juvenil pressupõe uma relação dinâmica entre educação, conhecimento, participação, responsabilização e criatividade, com mecanismos que fortaleçam a perspectiva da educação para uma cidadania ética e responsável, através das formas de expressão juvenil (SOUZA; SOUZA, 2019).

Neste sentido, para que a pessoa seja um agente transformador, ela deve estar imersa no cotidiano e na história ao mesmo tempo. Fazendo-se necessário que os projetos escolares estejam em consonância com as medidas de promoção do protagonismo e da educação juvenil dos alunos (FREIRE apud PEREIRA, 2020).

As práticas e políticas pedagógicas são consideradas atuantes diretas neste processo de protagonismo, uma vez que, a educação é responsável pela promoção da autonomia do educando (PEREIRA, 2020).

Deste modo, a Lei de Diretrizes e Bases da Educação Nacional (LDBEN) estabelece em seu art $2^{-}$, que a educação é dever da família e do estado, devendo ser inspirada em liberdade, e com finalidade de exercer o exercício da cidadania e a qualificação do educando para o trabalho (LDBEN apud JESUS, 2020).

Amparado a essa lógica SOUZA e SOUZA (2019) afirmam que com o avanço da globalização, a educação tornou-se um bem de consumo, que através de práticas e políticas afloram a oportunidade de um crescimento mais estruturado onde as pessoas serão protagonistas da sua própria vida.

Assim, a educação para a participação significa criar espaços nos quais possam compreender a construção do próprio ser. Sendo as práticas e experiências o melhor caminho a percorrer, desde a infância até os dias de hoje (SILVA et al, 2018).

Diante disso, REIS (apud SILVA, 2019) relata que as escolas precisam de um olhar mais atento para as políticas pedagógicas, onde sejam articulados pelos educadores questões de cunho social e econômico, a fim de valorizar e consolidar os saberes dos educandos.

Ainda segundo REIS (apud SILVA, 2019), educar sob a perspectiva do protagonismo infanto-juvenil demanda uma contratante atualização de práticas e saberes pedagógicos, uma vez que, exige diálogos complexos com a problematização do mundo real e conhecimentos de informações globais. 
A saber, a Política Nacional do EA (PNEA) estabelece que devem ser desenvolvidas através de uma prática educativa, modalidades contínuas e permanentes que promovam a participação de todos os níveis escolares na educação integrada, com enfoque holístico, cultural, socioeconômico e político (JESUS, 2020).

Além disso, o protagonismo infanto-juvenil nas escolas é difundido através das Diretrizes Circulares Nacionais, que regem um conjunto de princípios a serem observados nas escolas. Estes vinculam à educação as práticas sociais (PEREIRA, 2020).

Um exemplo disso é o Art. 2º , afirmando que a educação deve ser fundamentada em interesses sociais, respeitando a ordem democrática e fortalecendo vínculos com a família, solidariedade humana e reciprocidade (PEREIRA, 2020).

Diante disso, fica evidenciado no documento de Diretrizes e práticas pedagógicas que as escolas devem assimilar as mudanças oriundas da globalização, adaptando as novas formas de ensino e encarando as exigências da sociedade pósmoderna (SOUZA; SOUZA, 2009).

Ainda de acordo com os autores, a mediação pode ser entendida como uma prática de promoção do protagonismo infanto-juvenil, enfatizando diálogo entre os jovens e educadores por meio da cooperação e mudança na forma da administração escolar (SOUZA; SOUZA, 2009).

Para tanto, os alunos e professores devem ser capazes de contribuir igualitariamente no desenvolvimento de concepções da escola, rompendo barreiras paternalistas da cultura brasileira, e tornando a instituição dinâmica, protagonizada na resolução de conflitos (PEREIRA, 2020).

Ainda sobre esses aspectos, Silva et al (2018) aponta que o respeito ao bem comum e o protagonismo infanto-juvenil está bem ressaltada nos documentos oficiais do Brasil, de modo que, a fase atual pode ser entendida como uma concepção moderna de cidadania.

Assim, Faretti (apud PEREIRA, 2020) relata que o protagonismo social está sendo promovido através de práticas sociais nas escolas, remetendo a noção de hibridismo e a posição moderna da cidadania da população infanto-juvenil. 
Portanto, pode-se afirmar que é vasto e difícil enfrentar as múltiplas dimensões que o ato de participação implica. Além do engajamento ético, a opção de desenvolver propostas a partir do protagonismo infanto-juvenil exige do educador e a instituição, uma clara vontade política de contribuir neste processo por meio de seu trabalho (SILVA, 2019).

\section{CONCLUSÃO}

O objetivo do presente estudo o objetivo do presente estudo foi realizar uma revisão integrativa da literatura a fim de compreender as políticas e práticas pedagógicas envolvidas na promoção de potencialidades da escola para o impulsionamento do protagonismo infanto-juvenil

Conhecer os jovens e as problemáticas da atualidade é importante para desenvolver propostas pedagógicas adequadas e capazes de ofertar oportunidades e espaços que lhes permitam assumir responsabilidades, autonomia, consciência crítica e, para o desenvolvimento da cidadania.

Deste modo, com os problemas cotidianos de sua comunidade, o protagonismo infanto-juvenil se mostra como um dos mecanismos de fortalecimento da educação para a cidadania ética.

Portanto, este promove a formação da identidade, a autoimagem e a autoestima, sendo sua autonomia considerada o núcleo do próprio protagonismo. Assim, as reflexões e consciências críticas de questões atuais exigem um posicionamento da sociedade como um todo, na qual os jovens estão inseridos.

Conclui-se através da pesquisa realizada que existem diversos documentos que promovem as práticas e políticas do protagonismo nas escolas, todavia estas dependem da participação efetiva dos gestores e educadores.

Dito isso, as escolas devem vistas pela população infanto-juvenil como um espaço para se expressar e desenvolver atitudes saudáveis e responsáveis, ensaiando passos para se tornarem cidadãos esclarecidos sobre seus direitos e deveres, participando ativamente da mudança da sua comunidade. 


\section{REFERÊNCIAS}

BATISTA, Marisa. O protagonismo infantojuvenil e suas competências empreendedoras como iniciativas educativas e profissionais numa organização social e ética. Revista Atlas. 2020.

FREIRE, Paulo. Pedagogia da Autonomia: Saberes necessários à prática educativa. São Paulo: Paz e Terra, zoII Pedagogy of the oppressed (revised). New York: Continuum, 1996.

JESUS, Leandra Fernandes Alves de. Protagonismo juvenil no diálogo sobre água: um relato de experiência sobre a conferência de meio ambiente na escola. Revista Brasileira do Ensino Médio.2020. doi:I0.528I/zenodo.401126IElectronic ISSN: 2595$8 \mathrm{r} 6 \mathrm{X}$.

LIBÂNEO, José Carlos. Pedagogia e Pedagogos, Para quêe. 8 ed. São Paulo: Cortez, 2005 .

REIS, Edmerson dos Santos. O projeto político-pedagógico nas escolas do campo: um instrumento essencial. In: LIMA, Elmo de Souza; SILVA, Ariosto da Silva. (Orgs.). Diálogos sobre educação do campo. Teresina: PI: EDUFPI, 2011. 173-188.

SILVA, Suse Gomes da Costa. Escola do Campo: quais as possibilidades de inovação nas práticas pedagógicas?. Tese de Doutorado. 2019

SILVA, Juliana Pereira et al. Promoção da saúde na educação básica: percepções dos alunos de licenciatura em enfermagem. Rev Gaúcha Enferm. 2018;39:e20170237. doi: https://doi.org/10.1590/1983-1447.2018.2017-0237.2018. 
SOUZA, Edsonia Jadma Marcelino; SOUZA, Alexander Pelissari. A mediação escolar como método adequado de solução de conflitos e fortalecimento do protagonismo juvenil. Temas \& Matizes, v. 13, n. 24. 2019.

TOGNETTA, Luciene Regina Paulino; DAUD, Rafael Petta. Quem educa em um ambiente educacional? O legado piagetiano para pensar a convivência ética na escola e o papel da autoridade e do protagonismo infanto-juvenil. Revista eletrônica de psicologia e epistemologia genéticas.2017

PINTO, Maria Benegelania. Promoção da saúde e a relação entre escola e comunidade: potencialidades para a transformação social. 2019.

PEREIRA, Rosemere. Protagonismo juvenil na escola cidadã integral: da concepção às vivências. Campina Grande. 2020. 